\title{
The Relationship Between Dental Disease and Cerebral Vascular Accident in Elderly United States Veterans
}

\author{
Walter J. Loesche,* Anthony Schork, † Margaret S. Terpenning, $\ddagger \S$ Yin-Miao Chen, $\dagger$ \\ Connie Kerr, „| and B. Liza Dominguez \\ * University of Michigan, School of Dentistry, Department of Biologic and Materials Science, Ann Arbor, MI. \\ + School of Public Health, Department of Biostatistics. \\ ¥ Veterans Affairs Medical Center, Ann Arbor, MI. \\ $\S$ University of Michigan, School of Medicine, Department of Internal Medicine, Division of Geriatric Medicine. \\ \| School of Nursing.
}

\section{Abstract}

We report here information obtained from a cross-sectional study of 401 veterans, who were at least 60 years of age, which showed that several dental/oral conditions can be significantly associated with the diagnosis of a cerebral vascular accident (CVA), when included in a multivariate logistic regression model with and without many of the known risk factors for a CVA. The dental findings relative to the prevalence of dental caries and periodontal disease were not distinctly different between the subjects with and without a CVA in the bivariate analysis. A higher stimulated salivary flow was negatively associated with a CVA in the multivariate models. The plaque index and oral hygiene habits relating to brushing, flossing, and frequency of having teeth cleaned by a dentist/hygienist were significantly associated with a CVA in the bivariate analysis. Among these oral hygiene parameters, "needing help in brushing one's teeth" and the reported annual visit to the dentist/hygienist for teeth cleaning remained significant in the multivariate models involving the dependent-living subjects. The need for help in brushing one's teeth could reflect the fact that many subjects had reduced manual dexterity as a result of the CVA and required this extra care. However, the finding that those dependent-living individuals who reported that they did not have their teeth cleaned at least once a year were
\end{abstract}

4.76 times more likely to have had a CVA, suggests that a pattern of oral neglect might be associated with developing a CVA. The implications of this in terms of an intervention strategy for CVA warrants further consideration. However, caution is recommended because the data were obtained from a convenience sampling of older veterans and may not be generalizable to other populations. Ann Periodontol 1998;3:161-174.

Key Words: Cerebrovascular diseases/epidemiology; oral hygiene; periodontal diseases/complications; elderly; veterans. 


\section{INTRODUCTION}

The role of a preceding febrile infection, mostly bacterial infections of the respiratory tract, as a risk factor for ischemic brain infarction or stroke was demonstrated by Syrjanen et al. by using a case-control design. ${ }^{1}$ Subsequently, in a subset of the same subjects, dental infections, primarily periodontal disease, could also be associated with a cerebral vascular accident (CVA). ${ }^{2}$ The linking of dental infections with a CVA is novel, as the only connection previously had been the indirect one in which dental infections, and treatment of such, had been associated with bacterial endocarditis, ${ }^{3}$ and patients with endocarditis have a $20 \%$ chance of developing a CVA during the course of their illness. ${ }^{4}$ However, in this linkage of dental disease with a CVA, the confounding effect of the respiratory tract infections was not accounted for, so that it is possible that the importance of chronic dental infections might disappear if other febrile infections had been included in the analysis. There is suggestive evidence of a relationship between dental infections and respiratory tract infections that could undermine the direct importance of the dental infections. For example, extraction of third molars may predispose a person to respiratory tract infections, ${ }^{5}$ and periodontal disease has been suggested as the source of some of the salivary bacteria that, after aspiration, can be cultured from lung abscesses. ${ }^{6,7}$ In a recent case-control study in which dental, respiratory, and ear, nose and throat infections were evaluated in age-adjusted multiple logistic regression analysis, poor dental status was independently associated with cerebral vascular ischemia. ${ }^{8}$

This finding that dental disease was associated with CVA after adjusting for other chronic infections lends credence to other studies in which the effect of chronic infections was not accounted for. In a prospective study of United States veterans participating in a longitudinal aging study, the presence of alveolar bone loss was associated with the subsequent diagnosis of a stroke. ${ }^{9}$ Individuals with "high" bone loss were 2.8 times more likely to develop a stroke than individ- uals with "low" bone loss, even when such known risk factors for stroke such as age, smoking, non-insulin-dependent diabetes, diastolic blood pressure, family history of stroke, and education were included in the multivariate analysis. Other studies have shown a connection between dental disease and coronary heart disease via mechanisms that can be applied to explain the association between dental disease and a CVA.9-15 Thus, the presence of a contained infection and inflammatory response in the periodontium which sends inflammatory cytokines, lipopolysaccharides (LPS), and even bacteria into the systemic circulation provides sufficient mechanisms by which dental disease, especially periodontal disease, could be capable of contributing to the onset of a CVA.

We have been recording a large number of oral/dental variables in a group of elderly veterans to study the relationship between oral/dental health and systemic diseases among older individuals. ${ }^{16,17}$ We report here information obtained from a cross-sectional study of older U.S. veterans which shows that several dental/oral conditions can be significantly associated with the diagnosis of a CVA, when included in a multivariate logistic regression model along with and without many of the known risk factors for a CVA.

\section{MATERIALS AND METHODS}

\section{Subjects}

A convenience sample of 401 veterans, who were at least 60 years of age, was recruited from the dental outpatient clinic of the Ann Arbor Veterans Administration (VA) Hospital $(n=206)$, from a long-term care facility associated with the hospital $(n=114)$, and from an acute care ward $(n=81)$ where some had been recently admitted because of swallowing difficulties. There were no age, gender, racial, or educational differences among the subjects entered from the independent-living, dental outpatient clinic, and the 2 dependent-living locations, which led us to initially combine all the subjects in a single group for statistical analysis. The long-term care and acute care subjects had significantly more edentulism compared to 
the outpatients and a higher reported history of stroke. ${ }^{16}$ Because of this, a separate variable indicating whether the participant entered from an independent or dependent nursing home or acute care ward was included in the multivariate analysis to account for any confounders that might be introduced as a result of entry site.

\section{Dental and Medical Health Questionnaire}

A structured questionnaire was administered by trained interviewers to the participants to elicit information about demographic characteristics, medical and dental history, dietary preferences, dry mouth complaints, and use of medications, among other parameters. ${ }^{16}$ At the conclusion of the questionnaire, the interviewer scored each participant on a scale of 1 to 5 for the degree of comprehension and cooperation in answering the questionnaire. This score was included in the multivariate models as a means of adjusting for any reduced mental awareness of the subjects who entered from the dependent-living situations.

\section{Dental Variables}

The number of teeth and the number of restorations and decay on all tooth surfaces were determined by a clinical examination. The presence and type of dentures and other prosthetic devices were recorded. The subjects were stratified into a low tooth number group, i.e., those subjects with 1 to 14 teeth, and a high tooth number group, i.e., those with 15 to 28 teeth. This partition was guided by the fact that subjects with 1 to 14 teeth could be wearing a full denture, whereas it would be impossible to wear a full denture if 15 to 28 teeth were present. Third molars, which were rarely present in these older subjects, were omitted from all analysis. Periodontal probing depths, attachment levels, and gingival recession around all teeth were measured with an automated pressure-sensitive periodontal probe ${ }^{x}$ and

IIInterprobe, The Dental Probe, Inc., Richmond, VA. recorded electronically. Oral hygiene was assessed by the plaque index (PI), ${ }^{18}$ and gingivitis with the papillary bleeding score (PBS). ${ }^{18,19}$ The average PI and PBS for each subject was determined by summing the PIs and PBSs of the individual teeth, and then dividing by the number of teeth. These average PIs and PBSs for the whole mouth were then used in the statistical analysis. The subjects were also asked how often they brushed and flossed their teeth, if they needed help in brushing their teeth and dentures, and how often they visited their dentist/hygienist to have their teeth cleaned.

\section{Salivary and Swallowing Variables}

Salivary flow was stimulated by applying citric acid to the tongue and collecting the subsequent saliva. ${ }^{16}$ The amount of saliva collected in 3 or 5 minutes was measured gravimetrically, and its $\mathrm{pH}$ and bacterial composition were determined. ${ }^{20}$ The resting salivary flow was estimated from the amount of mucosal wetness, " using filter papers applied to the inside lip, cheek, and palate. ${ }^{21}$ The presence of a complaint of xerostomia was elicited by asking multiple questions concerning dryness. ${ }^{22}$ The number of medications used by the subjects was obtained by interview and from examination of a computerized record of medications maintained by the Department of Veterans Affairs. The answers to questions relating to difficulty in swallowing, as well as a history of dysphagia, were obtained from the interview. Questions were also asked concerning difficulty in chewing, and the subject's eating preferences, food avoidances, and whether dentures were worn only during eating. ${ }^{16,17}$

\section{Medical Variables}

The presence of CVA was ascertained from the patient during the interview and by a thorough examination of the patient's medical record. In this report, CVA had to be a medically established diagnosis in the patient's medical record, which was based upon brain lesions demonstrable by $\mathrm{C}$ -

\#Periotron, ORAFLOW, Inc., Plainview, NY. 
scans, and physical and neurological examinations that established the extent of the physical impairment. Systolic and diastolic blood pressures and blood cholesterol values were obtained from the medical records. The patient's weight and height were obtained during the dental examination and used to calculate the body mass index (BMI). The patient's cognitive status was estimated at the end of the interview on a 5-point scale, ranging from excellent to very poor, by the interviewer.

\section{Statistical Methods}

Summary statistics are presented as means \pm standard deviations and frequencies with percentages as appropriate. Statistical tests consisted of chi-square analyses for categorical data. After extensive investigation of transformation of the continuous measures, it was concluded that normality was not obtainable, so non-parametric Wilcoxon rank sum or Kruskal-Wallis tests were used. Based on these initial analyses, candidate predictor $(P<0.25)$ variables were entered into multiple logistic analyses until a "best" model was derived. Two full models were developed: one that included all subjects but excluded the tooth variables, i.e., the "all subjects" model; and one that was restricted to the dentate subjects but included the dental variables, i.e., the "dentate subjects" model. In the "all subjects" model, we would be able to observe the effect of variables such as salivary flow and swallowing independent of the tooth-related variables, whereas in the "dentate subjects" model any effect of being edentulous and wearing dentures would not be considered. These models consisted of predictors with dental relevance and/or statistical significance, as well as many of the recognized risk factors for CVA, i.e., diabetes, smoking history, current use of alcohol, age, BMI, blood pressure, and serum cholesterol levels. Based on analyses of these full models, candidate predictor variables $(P<0.25$ in the full model) were entered into reduced models until a model was obtained that combined the highest likelihood ratio with the fewest degrees of freedom. In this reduced model, the non-significant variables were then added back, one at a time, to the model containing the significant variables to determine their individual effect on the model.

\section{RESULTS}

The 401 subjects were recruited from 3 locations within the VA hospital, 2 of which were dependent-living groups chosen to increase the number of patients with a diagnosis of a CVA. Thus, while $16 \%$ of the dental outpatient group had a medical diagnosis of a CVA, more than twice as many, or $38 \%$ of the nursing home residents and $40 \%$ of the acute care patients, had a CVA. There were no differences between the subjects from the various entry sites in terms of average age (67.8 to 70 years), gender ( $92 \%$ to $100 \%$ male), race ( $81 \%$ to $94 \%$ white), education, place of residence, or economic status, which led us initially to combine all subjects into a single convenience sample to determine the relationship between dental status and CVA.

Twenty-two percent (22\%) of the dentate subjects and $30 \%$ of the edentulous subjects had been diagnosed with a CVA, giving an overall prevalence of $26.7 \%$ among our study population. This stratification of subjects, based upon the presence of teeth, was not associated with any difference between subjects with and without a diagnosis of CVA in terms of age, or many of the recognized risk factors for CVA, such as smoking history, alcohol consumption, serum cholesterol levels, or blood pressure (Table 1). Subjects with a CVA had a lower body mass index (BMI), were taking more medications, and tended to have less schooling. Although there were only 31 African-Americans in the study, they were significantly more likely to have a diagnosis of a CVA. The edentulous subjects, compared to the dentate subjects, were more likely to be current smokers, but being a current smoker could not be associated with a CVA (Table 1).

The stimulated salivary flow was significantly reduced in both the dentate and edentulous subjects with a CVA compared to subjects without a CVA, whereas the resting saliva tended to be higher in the subjects 
Table 1. Distribution of demographic characteristics and recognized risk factors for cerebral vascular accident (CVA) in older U.S. veterans

\begin{tabular}{|c|c|c|c|c|c|c|}
\hline \multirow[b]{2}{*}{ Risk Factors/Indicators } & \multicolumn{2}{|c|}{$\begin{array}{c}\text { Dentate Subjects } \\
\text { CVA Status }\end{array}$} & \multicolumn{2}{|c|}{$\begin{array}{c}\text { Edentulous Subjects } \\
\text { CVA Status }\end{array}$} & \multicolumn{2}{|c|}{$\begin{array}{l}\text { All Subjects } \\
\text { CVA Status }\end{array}$} \\
\hline & $\begin{array}{c}\text { No } \\
n=188\end{array}$ & $\begin{array}{c}\text { Yes } \\
n=61\end{array}$ & $\begin{array}{c}\text { No } \\
n=106\end{array}$ & $\begin{array}{c}\text { Yes } \\
n=46\end{array}$ & $\begin{array}{c}\text { No } \\
n=294\end{array}$ & $\begin{array}{c}\text { Yes } \\
n=107\end{array}$ \\
\hline \multirow[t]{2}{*}{ Age in years } & $68.2(5.3)^{\star}$ & $68.8(5.9)$ & $67.9(6.4)$ & $69.2(6.3)$ & $68.1(5.7)$ & $69.0(6.0)$ \\
\hline & & & \multicolumn{2}{|c|}{$P=0.05^{\dagger}$} & \multicolumn{2}{|c|}{$P=0.05$} \\
\hline \multicolumn{7}{|l|}{ Race } \\
\hline European-American & $90.8 \%$ & $85.0 \%$ & $94.3 \%$ & $79.1 \%$ & $92.1 \%$ & $82.5 \%$ \\
\hline African-American & $6.5 \%$ & $11.7 \%$ & $2.9 \%$ & $20.4 \%$ & $5.2 \%$ & $15.5 \%$ \\
\hline \multirow[t]{2}{*}{ Other } & $2.7 \%$ & $3.3 \%$ & $2.9 \%$ & - & $2.8 \%$ & $1.9 \%$ \\
\hline & & & & & \multicolumn{2}{|c|}{$P=0.05$} \\
\hline \multicolumn{7}{|l|}{ Education } \\
\hline$<8$ years & $17.9 \%$ & $28.3 \%$ & $25.0 \%$ & $28.6 \%$ & $20.5 \%$ & $28.4 \%$ \\
\hline $9-12$ years & $48.4 \%$ & $48.3 \%$ & $57.7 \%$ & $64.3 \%$ & $51.7 \%$ & $54.9 \%$ \\
\hline \multicolumn{7}{|l|}{ Ever smoke } \\
\hline No & $17 \%$ & $8 \%$ & $5 \%$ & $10 \%$ & $13 \%$ & $9 \%$ \\
\hline Yes & $83 \%$ & $92 \%$ & $95 \%$ & $90 \%$ & $87 \%$ & $91 \%$ \\
\hline Current smoker & $18 \%$ & $18 \%$ & $35 \%$ & $33 \%$ & $24 \%$ & $25 \%$ \\
\hline \multicolumn{7}{|l|}{ Drink alcohol } \\
\hline No & $45 \%$ & $44 \%$ & $53 \%$ & $50 \%$ & $48 \%$ & $47 \%$ \\
\hline Occasionally & $42 \%$ & $36 \%$ & $34 \%$ & $36 \%$ & $39 \%$ & $36 \%$ \\
\hline Daily & $12 \%$ & $20 \%$ & $13 \%$ & $14 \%$ & $13 \%$ & $18 \%$ \\
\hline Number of medications & $6.9(4.1)$ & $9.0(4.5)^{\ddagger}$ & $8.5(4.9)$ & $9.5(3.8)$ & $7.5(4.5)$ & $9.2(4.2)^{\ddagger}$ \\
\hline Body mass index & $26.9(5.2)$ & $26.2(5.3)$ & $25.7(7.4)$ & $24.6(4.7)$ & $26.8(6.1)$ & $25.5(5.1)^{\ddagger}$ \\
\hline \multicolumn{7}{|l|}{ Blood pressure } \\
\hline Systolic & $143(21)$ & $135(23)$ & $137(23)$ & $137(22)$ & $140(22)$ & $136(22)$ \\
\hline Diastolic & $74(11)$ & $73(11)$ & $76(14)$ & $73(13)$ & $75(13)$ & $73(12)$ \\
\hline
\end{tabular}

*Standard deviation in parentheses.

tChi-square or Fisher's exact test.

tValues are significantly different from corresponding "No" value, with $P<0.05$, Wilcoxon test.

Table 2. Distribution of salivary and swallowing variables in subjects with and without a cerebral vascular accident (CVA)

\begin{tabular}{|c|c|c|c|c|c|c|}
\hline \multirow[b]{2}{*}{ Oral Variables } & \multicolumn{2}{|c|}{$\begin{array}{c}\text { Dentate Subjects } \\
\text { CVA Status }\end{array}$} & \multicolumn{2}{|c|}{$\begin{array}{c}\text { Edentulous Subjects } \\
\text { CVA Status }\end{array}$} & \multicolumn{2}{|c|}{$\begin{array}{l}\text { All Subjects } \\
\text { CVA Status }\end{array}$} \\
\hline & $\begin{array}{c}\text { No } \\
n=188\end{array}$ & $\begin{array}{c}\text { Yes } \\
n=61\end{array}$ & $\begin{array}{c}\text { No } \\
n=106\end{array}$ & $\begin{array}{c}\text { Yes } \\
\mathrm{n}=46\end{array}$ & $\begin{array}{c}\text { No } \\
n=294\end{array}$ & $\begin{array}{c}\text { Yes } \\
n=107\end{array}$ \\
\hline \multicolumn{7}{|l|}{ Salivary variables } \\
\hline $\mathrm{pH}$ & $6.5(0.7)^{\star}$ & $6.5(0.8)$ & $6.0(1.0)$ & $6.3(0.8)$ & $6.4(0.9)$ & $6.5(0.8)$ \\
\hline Resting $\mu \mathrm{g} /$ minute & $2.8(1.2)$ & $3.1(1.4)$ & $2.9(1.3)$ & $3.0(1.3)$ & $2.8(1.2)$ & $3.0(1.4)$ \\
\hline Stimulated $\mathrm{mL} /$ minute & $0.7(0.3)$ & $0.5(0.3)^{\dagger}$ & $0.6(0.3)$ & $0.5(0.2)^{\dagger}$ & $0.7(0.3)$ & $0.5(0.3)^{\dagger}$ \\
\hline \multicolumn{7}{|l|}{ Complaint of mouth } \\
\hline Dry while eating & $11 \%$ & $20 \%$ & $10 \%$ & $13 \%$ & $10 \%$ & $17 \%$ \\
\hline Dry any time & $74 \%$ & $78 \%$ & $78 \%$ & $64 \%$ & $76 \%$ & $72 \%$ \\
\hline \multicolumn{7}{|l|}{ Swallowing variables } \\
\hline History of dysphagia & $33 \%$ & $40 \%$ & $21 \%$ & $36 \%$ & $29 \%$ & $38 \%$ \\
\hline Difficulty swallowing & $33 \%$ & $34 \%$ & $21 \%$ & $33 \%$ & $29 \%$ & $34 \%$ \\
\hline Difficulty chewing & $16 \%$ & $28 \%{ }^{\ddagger}$ & $26 \%$ & $22 \%$ & $20 \%$ & $25 \%$ \\
\hline Avoids any food & $18 \%$ & $27 \%$ & $31 \%$ & $48 \%$ & $23 \%$ & $35 \%^{\ddagger}$ \\
\hline
\end{tabular}

"Standard deviation in parentheses.

t"Yes" values are significantly different from corresponding "No" value, with $P<0.05$, Wilcoxon test.

f"Yes" values are significantly different from corresponding "No" value, $P<0.05$, chi-square or Fisher exact test. 
Table 3. Dental variables in older dentate veterans with and without a cerebral vascular accident (CVA)

\begin{tabular}{lccc}
\hline & \multicolumn{2}{c}{ Cerebral Vascular Accident } & \\
\cline { 2 - 3 } \multicolumn{1}{c}{ Dental Parameter } & No $(\mathrm{n}=188)$ & Yes $(\mathrm{n}=61)$ & Significance \\
\hline Number of teeth & $17.8(7.1)^{\star}$ & $16.8(7.5)$ & $P=0.12$ \\
$\quad$ Decayed & $2.8(3.0)$ & $3.7(3.6)$ & 0.154 \\
Restored & $8.0(5.7)$ & $6.0(5.4)$ & 0.059 \\
$\quad$ Missing & $10.2(7.1)$ & $11.2(7.5)$ & $>0.2$ \\
Presence of dentures & & & \\
Any type & $53 \%$ & $46 \%$ & $>0.2$ \\
Full & $23 \%$ & $26 \%$ & $>0.2$ \\
\% of teeth with: & & & \\
Probing depth $\leq 3 \mathrm{~mm}$ & $58 \%(25)$ & $54 \%(28)$ & $>0.2$ \\
Probing depth 4-6 mm & $35 \%(21)$ & $39 \%(22)$ & $>0.2$ \\
Probing depth $>6 \mathrm{~mm}$ & $7 \%(14)$ & $7 \%(14)$ & $>0.2$ \\
Attachment loss $\leq 3 \mathrm{~mm}$ & $38 \%(27)$ & $33 \%(28)$ & $>0.2$ \\
Attachment loss 4-6 mm & $50 \%(23)$ & $46 \%(23)$ & $>0.2$ \\
Attachment loss $>6 \mathrm{~mm}$ & $12 \%(20)$ & $21 \%(26)^{\dagger}$ & $0.028^{\dagger}$ \\
\hline
\end{tabular}

*Average, with standard deviation in parentheses.

tDifference between groups is significant, Wilcoxon, $P<0.05$.

with a CVA (Table 2). Most subjects complained of dryness at some time during the day, but the complaint could not be related to the presence of a CVA or teeth. However, the subjects with a CVA were more likely to complain of dryness while eating, possibly reflecting their reduced stimulated salivary flow. Subjects with CVA were more likely to report a history of dysphagia and tended, especially among the edentulous subjects, to report more difficulties in swallowing than the non-CVA subjects. Dentate subjects with a CVA were significantly more likely to report some difficulty in chewing foods. Subjects with a CVA were more likely to avoid certain foods, i.e., crunchy and chewy foods.

We examined in more detail the toothrelated parameters in the dentate subjects with and without a CVA. The dentate subjects with a CVA tended to have fewer teeth and fewer restored teeth than the dentate subjects without a CVA (Table 3). Because of the many missing teeth in our subjects, the prevalence of decay and periodontal morbidity were calculated as a percentage of the involved teeth in each subject. There was no difference in the percentage of teeth with decay in subjects with and without a CVA (data not shown). About $50 \%$ of the subjects with and without a CVA wore a denture of some type. The percentage of teeth with probing depths and attachment loss $<4 \mathrm{~mm}$, and 4 to $6 \mathrm{~mm}$, did not differ between the subjects with and without a CVA, but $21 \%$ of the teeth in the subjects with a CVA had attachment loss $>6 \mathrm{~mm}$ compared to $12 \%$ of the teeth in subjects without a CVA $(P=0.028)$ (Table 3).

About $70 \%$ of the dentate subjects had poor oral hygiene, as judged by the presence of visible plaque, i.e., a whole-mouth average PI $>1$. However, the $84 \%$ prevalence of visible plaque among the CVA subjects was significantly higher than the $61 \%$ among subjects without a CVA (Table 4). The subjects with a CVA also had a significantly higher proportion of bleeding gingivitis, i.e., $27 \%$ with a whole-mouth average papillary bleeding score (PBS) $>2$ compared to $13 \%$ in the subjects without a CVA. Ninety-six percent $(96 \%)$ of the non-CVA subjects reported brushing their teeth daily, which was significantly higher than the $84 \%$ prevalence reported by the CVA subjects. Thirty-five percent $(35 \%)$ of the non-CVA subjects reported that they flossed their teeth daily compared to $18 \%$ of the CVA subjects. Not surprisingly, significantly more CVA subjects needed help in brushing their teeth. Fifty-seven percent (57\%) of the CVA patients reported having their teeth cleaned at least yearly, which was significantly less than the $80 \%$ frequency reported by the non-CVA subjects (Table 4). 
Table 4. Oral hygiene parameters and habits in older dentate veterans with and without a cerebral vascular accident (CVA)

\begin{tabular}{lccc}
\hline \multirow{2}{*}{ Dental Parameter } & \multicolumn{2}{c}{ Cerebral Vascular Accident } & \\
\cline { 2 - 3 } & No $(\mathrm{n}=188)$ & Yes $(\mathrm{n}=61)$ & Significance \\
\hline Plaque index & & & \\
$\quad \%$ of subjects $\leq 1$ & $39 \%$ & $16 \%$ & $<0.001^{*}$ \\
$\%$ of subjects $>1$ & $61 \%$ & $84 \%$ & \\
Papillary bleeding score & & & 0.019 \\
$\%$ of subjects $\leq 2$ & $87 \%$ & $73 \%$ & \\
$\%$ of subjects $>2$ & $13 \%$ & $27 \%$ & 0.001 \\
Brush daily & $96 \%$ & $84 \%$ & 0.003 \\
Floss daily & $35 \%$ & $18 \%$ & 0.016 \\
Need help brushing & $3 \%$ & $12 \%$ & 0.003 \\
Teeth cleaned yearly by hygienist & $80 \%$ & $57 \%$ & \\
\hline
\end{tabular}

${ }^{*}$ Difference between groups is significant, chi-square or Fisher's exact test.

Table 5. Relationship between dental/oral parameters and cerebral vascular accident (logistic regression analysis-reduced models $^{\star}$ )

\begin{tabular}{|c|c|c|c|c|}
\hline & \multicolumn{4}{|c|}{ All Subjects } \\
\hline & \multicolumn{2}{|c|}{ All $(n=380)^{\dagger}$} & \multicolumn{2}{|c|}{ Dentate $(n=232)$} \\
\hline & $\mathrm{LR}=71.5$ & $7 \mathrm{DF}$ & $L R=56.2$ & $9 \mathrm{DF}$ \\
\hline & \multicolumn{2}{|c|}{$P=0.0001$} & \multicolumn{2}{|c|}{$P=0.0001$} \\
\hline Parameters & Odds Ratio & $95 \% \mathrm{Cl}^{\ddagger}$ & Odds Ratio & $95 \% \mathrm{Cl}$ \\
\hline Resting saliva & 1.20 & $0.98-1.47$ & 1.31 & $0.99-1.73$ \\
\hline Stimulated saliva & $0.20^{\S}$ & $0.07-0.57$ & 0.32 & $0.09-1.16$ \\
\hline $\begin{array}{ll}\text { Teeth } & 0 \\
& 1-14 \\
15-28\end{array}$ & & & $\begin{array}{l}1.0 \\
3.29 \S\end{array}$ & $1.33-8.16$ \\
\hline Current alcohol use & & & & \\
\hline None & 1.0 & & & \\
\hline Occasional & 1.21 & $0.68-2.15$ & & \\
\hline Daily & $2.25^{\S}$ & $1.05-4.79$ & & \\
\hline African-American & $3.22^{\S}$ & $1.33-7.77$ & & \\
\hline $\begin{array}{l}\text { Need heip brushing } \\
\% \text { teeth with: }\end{array}$ & $3.93^{\S}$ & $1.43-10.8$ & 2.88 & $0.62-13.42$ \\
\hline Attachment $>6 \mathrm{~mm}$ & & & $1.04 \S$ & $1.01-1.07$ \\
\hline Probing depth $>6 \mathrm{~mm}$ & & & 0.96 & $0.92-1.01$ \\
\hline Plaque index $>1$ & & & 1.81 & $0.76-4.35$ \\
\hline Annual teeth cleaning & & & 0.62 & $0.26-1.48$ \\
\hline Dependent living & $3.51^{\S}$ & $1.99-6.19$ & $3.2^{\S}$ & $1.41-7.28$ \\
\hline $\begin{array}{l}\text { LR }=\text { likelihood ratio. } \\
\text { DF }=\text { degrees of freedom. } \\
{ }^{*} \text { Age, smoking history, cho } \\
\text { significant in full model or } \\
{ }^{+} \text {Number of subjects is in } \\
{ }^{\star} \mathrm{Cl} \text { is confidence interval. } \\
\text { \$Values are significant at }\end{array}$ & $\begin{array}{l}\text { terol levels, } \\
\text { added bac } \\
\text { ntheses. } \\
0.05 \text {. }\end{array}$ & $\begin{array}{l}\text { diabetes, a } \\
\text { educed m }\end{array}$ & umber of mec & ions were no \\
\hline
\end{tabular}

All variables that had a bivariate significance of $P=0.25$, or were known risk factors/indicators for CVA, were placed into logistic regression models. Two general models were evaluated: one that included all subjects but omitted the tooth-related vari- ables (All subjects in Table 5), and one that included only the dentate subjects but with all the variables (Dentate subjects in Table 5). Also, because some of the parameters associated with a CVA in the bivariate analyses, such as number of medications taken 
Table 6. Relationship between dental/oral parameters and cerebral vascular accident (logistic regression analysisreduced models*)

\begin{tabular}{|c|c|c|c|c|c|c|c|c|}
\hline & \multicolumn{4}{|c|}{ Independent Subjects } & \multicolumn{4}{|c|}{ Dependent Subjects } \\
\hline & \multicolumn{2}{|c|}{ All $(n=201)^{\dagger}$} & \multicolumn{2}{|c|}{ Dentate $(n=152)$} & \multicolumn{2}{|c|}{ All $(n=177)$} & \multicolumn{2}{|c|}{ Dentate $(n=79)$} \\
\hline & \multicolumn{2}{|c|}{$P=0.41$} & $\begin{aligned} \mathrm{LR}= & 1.7 \\
& P=\end{aligned}$ & $P=0.77$ & $\begin{array}{r}\mathrm{LR}=32.09 \\
P=0\end{array}$ & 8 DF & \multicolumn{2}{|c|}{$P=0.0001$} \\
\hline Parameters & $\mathrm{OR}^{\ddagger}$ & $95 \% \mathrm{Cl}^{\ddagger}$ & OR & $95 \% \mathrm{Cl}$ & OR & $95 \% \mathrm{Cl}$ & OR & $95 \% \mathrm{Cl}$ \\
\hline Resting saliva & 1.32 & $0.89-1.96$ & & & 1.21 & $0.94-1.55$ & & \\
\hline Stimulated saliva & 0.64 & $0.14-3.02$ & 0.93 & $0.19-4.54$ & $0.05^{\S}$ & $0.01-0.23$ & $0.05^{\S}$ & $0.01-0.45$ \\
\hline Teeth 0 & 1.0 & & & & 1.0 & & & \\
\hline $1-14$ & 0.66 & $0.11-378$ & 1.0 & & 0.82 & $0.34-1.97$ & 1.0 & \\
\hline $15-28$ & 1.81 & $0.55-5.96$ & 1.79 & $0.48-6.7$ & 1.64 & $0.74-3.50$ & $3.79 \S$ & $1.15-12.59$ \\
\hline Current alcohol use & & & & & & & & \\
\hline None & 1.0 & & & & 1.0 & & & \\
\hline Occasional & 1.61 & $0.59-4.45$ & & & 1.01 & $0.49-2.11$ & & \\
\hline Daily & 2.0 & $0.52-7.72$ & & & $3.21^{\S}$ & $1.15-8.40$ & & \\
\hline African-American & 1.18 & $0.55-5.96$ & & & $3.23^{\S}$ & $1.16-8.96$ & & \\
\hline $\begin{array}{l}\text { Need help brushing } \\
\% \text { teeth with: }\end{array}$ & 3.38 & $0.31-36.3$ & 3.8 & $0.30-48.7$ & $4.96^{\S}$ & $1.43-17.1$ & $10.25^{\S}$ & $1.40-75.2$ \\
\hline Attachment $>6 \mathrm{~mm}$ & & & 1.00 & $0.97-1.03$ & & & $1.03^{\S}$ & $1.004-1.06$ \\
\hline Annual teeth cleaning & & & & & & & $0.21^{\S}$ & $0.06-0.69$ \\
\hline $\begin{array}{l}\text { DF = degrees of freed } \\
{ }^{*} \text { Age, smoking history, } \\
\text { back to reduced model } \\
{ }^{+} \text {Number of subjects in } \\
\text { } \text { OR is odds ratio; } \mathrm{Cl} \text { is } \\
\text { \$Values are significant }\end{array}$ & $\begin{array}{l}\text { lesterol } 1 \\
\text { enthese } \\
\text { nfidence } \\
0<0,05\end{array}$ & $\begin{array}{l}\text { Is, BMI, d } \\
\text { rval. }\end{array}$ & tes, an & nber of & cations we & ot signifi & in full model & when added \\
\hline
\end{tabular}

and the various oral hygiene parameters (i.e., needs help brushing, higher PI scores and papillary bleeding scores) could be a function of the dependent-living status, a separate variable for dependent living was added to the model. The inclusion of this variable was also supported by the finding that $9 \%$ of the nursing home subjects and $19 \%$ of the acute care subjects were judged to have poor comprehension of the questionnaire. In this regard, a second variable related to the interviewer's evaluation of the participants' response to the questionnaire was added to the model; but because it correlated with the variable for dependentliving status, it was dropped from the final models.

In the "all subjects" model, the only recognized risk factor for a CVA that was significant in the reduced model was the daily consumption of alcohol-containing beverages (OR $=2.25$, Table 5). Variables such as smoking history, blood cholesterol levels, BMI, and age were not significant either in the full model or when individually added back to the reduced model. A dependent-living status and being African-American were significantly associated with a CVA. Increased levels of stimulated saliva were negatively associated with a CVA, whereas a need by the subjects to have someone help them in brushing their teeth was positively associated with a CVA (Table 5).

In the "dentate subjects" model, increased levels of stimulated saliva and a dependentliving status remained significant, but the daily use of alcoholic beverages was no longer significant and was excluded from the model shown in Table 5. The dependent-living status remained significant, but being African-American was not significant. The presence of 15 to 28 teeth and an increased proportion of teeth with attachment loss $>6$ $\mathrm{mm}$ were significantly related to a CVA (Table 5). There was a tendency for the CVA subjects to have higher PIs and to not have an annual teeth cleaning visit with the dentist/hygienist. 
Table 7. Distribution of potential dental and oral hygiene risk indicators in subjects with 15 to 28 teeth with and without a cerebral vascular accident (CVA)

\begin{tabular}{|c|c|c|c|}
\hline & \multicolumn{2}{|c|}{ Cerebral Vascular Accident } & \multirow[b]{2}{*}{ Significance } \\
\hline & No $(n=129)$ & Yes $(n=42)$ & \\
\hline Number of teeth & $22.0(3.7)^{\star}$ & $21.2(3.7)$ & $P>0.2^{\dagger}$ \\
\hline$\%$ decayed & $3.5(8.4)$ & $5.1(6.3)$ & $P=0.02$ \\
\hline$\%$ probing depth > 4 mm & $43.1(21.8)$ & $40.8(27.2)$ & $P>0.2$ \\
\hline$\%$ attachment loss $>4 \mathrm{~mm}$ & $60.9(22.2)$ & $60.0(25.7)$ & $P>0.2$ \\
\hline$\%$ recession $>4 \mathrm{~mm}$ & $7.6(12.6)$ & $9.7(14.7)$ & $P>0.2$ \\
\hline \multicolumn{4}{|l|}{$\begin{array}{l}\text { Average whole mouth: } \\
\text { Papillary bleeding score }\end{array}$} \\
\hline$\leq 1$ & $88 \%$ & $79 \%$ & $P=0.16$ \\
\hline $\begin{array}{l}>1 \\
\text { Plaque index }\end{array}$ & $12 \%$ & $21 \%$ & \\
\hline$\leq 1$ & $43 \%$ & $24 \%$ & $P=0.032^{\ddagger}$ \\
\hline$>1$ & $57 \%$ & $76 \%$ & \\
\hline \% who: & & & \\
\hline $\begin{array}{l}\text { Brush daily } \\
\text { Floss daily }\end{array}$ & $\begin{array}{l}96 \% \\
40 \%\end{array}$ & $\begin{array}{l}82 \% \\
18 \%\end{array}$ & $\begin{array}{l}P=0.007^{\ddagger} \\
P=0.15\end{array}$ \\
\hline Visit dentist yearly & $88 \%$ & $64 \%$ & $P=0.001^{\ddagger}$ \\
\hline
\end{tabular}

*Average, with standard deviation in parentheses.

tValue is significantly different, Wilcoxon test.

‡Distribution is significantly different, chi-square.

The importance of dependent-living status in these models caused us to reanalyze the variables by using a separate model for the independent- and dependent-living subjects. None of the examined variables was found to be significant in the models examining the independent-living subjects (Table 6). In the "all subjects dependent living" model, the daily consumption of alcoholic beverages, being African-American, and needing help brushing one's teeth were positively associated with a CVA, whereas an increased flow of stimulated saliva was negatively associated or protective of a CVA. In the "dentate dependent living" model, the presence of 15 to 28 teeth, a higher proportion of teeth with attachment loss $>6 \mathrm{~mm}$, and a need by the subjects to have someone help them with brushing their teeth were significantly associated with a CVA. An increased flow of stimulated saliva and an increased reported frequency of an annual visit to the dentist/hygienist to have their teeth cleaned were significantly negatively associated with a CVA (Table 6).

The finding in the "dentate dependent living" subjects that individuals with 15 to 28 teeth were 3.8 times more likely to be in the
CVA group suggested that those subjects with 15 to 28 teeth and a CVA might have more dental disease relative to those subjects with 15 to 28 teeth and no CVA. However, except for a greater percentage of teeth with decay, there were no other differences in dental disease between the 2 groups (Table 7). When we examined the oral hygiene parameters and habits, the CVA subjects had a significantly higher percentage with a PI $>1$. Significantly fewer CVA subjects reported brushing their teeth daily and seeing their dentist/hygienist at least yearly for cleaning of their teeth (Table 7).

\section{DISCUSSION}

This cross-sectional study of dental/oral variables in a convenience sample of elderly veterans with or without a diagnosis of CVA confirmed previous studies that showed a significant association between certain aspects of dental disease and a CVA. ${ }^{2,8,9}$ It extended these studies by showing that oral variables such as stimulated salivary flow, many teeth, and certain oral hygiene habits or practices could be associated with a CVA. However, some caution in interpreting the 
data is necessary since our documentation of oral/dental and medical parameters was after the CVA event and certain findings, such as the need for help in brushing one's teeth, could be a result of the CVA. Also, because the data are obtained from survivors, it is possible that our findings would not apply to those individuals who had succumbed to stroke. For example, it may be that those who succumbed to stroke had fewer teeth, and that many teeth (i.e., 15 to 28 ) found by us to be a potential risk factor/indicator could, in reality, be a protective factor, occurring primarily in those individuals who had survived.

The prevalence of a CVA in our subjects, i.e., $27 \%$, was high because of our selection of older individuals, especially those living in a nursing home (38\% prevalence) and those recently admitted with a swallowing disorder to an acute care ward ( $40 \%$ prevalence). The presence of these subjects in a dependentliving situation led us to include living status as an independent variable in our models. While certain variables such as "needs help in brushing teeth," amount of stimulated saliva, having 15 to 28 teeth, and a high proportion of teeth with attachment loss $>6$ $\mathrm{mm}$ were independent variables that were significantly associated with a CVA in the "all subjects" model (Table 5), they were found to be characteristics primarily of the subjects recruited from a dependent-living situation. Thus, while there was a tendency for these variables to be associated with a CVA in the model confined to the independent-living subjects, they were each significantly associated with a CVA in the model confined to the dependent-living subjects (Table 6). In addition, those dependent-living subjects who reported having their teeth cleaned at least once a year were almost 5 times $(\mathrm{OR}=1.0 / 0.21=4.76)$ less likely to have a CVA than those subjects who did not report such an annual cleaning. This possible benefit of an annual cleaning was suggested in the "all subjects" model, but was not significant (Table 5).

The convenience nature of our study population, their advanced age, and the fact that they were receiving treatment for cardiovascular condition(s) probably explains why so few of the recognized risk factors for a CVA, i.e., age, BMI, blood pressure, cholesterol level, diabetes, and smoking, were not identified in the logistic modeling procedure. Insulin-dependent diabetes and the number of medications, or number of xerogenic medications, taken by the subject could be associated with a CVA in models that did not include the dependent-living variable, suggesting that they were surrogate markers for the dependent-living status of the participants. The daily consumption of alcoholic beverages was the only recognized risk factor that could be associated with a CVA and then only in the "all subjects" and "all dependent" subjects models. It was not a factor in the various dentate models (Tables 5 and 6). One drink per day has been shown to protect against a myocardial infarction, while 3 or more drinks per day is detrimental. ${ }^{23}$ Our questionnaire did not ascertain how many alcoholic drinks were consumed daily, so we cannot associate the amount of daily alcohol consumption with the likelihood of a CVA.

Only $8 \%$ of the subjects were AfricanAmerican, so it was unexpected that being African-American was a significant factor in having a CVA. This could reflect the convenience nature of our study group, since the Ann Arbor VA Hospital is the regional center for cardiovascular disease in the southeast area of Michigan. Individuals with a CVA would be referred from the Detroit area VA hospitals that have a large African-American clientele to the Ann Arbor Hospital, thereby enriching the African-American presence among our CVA subjects.

A higher stimulated salivary flow was negatively associated with a CVA in both the "all subjects" and "dependent subjects" models. This could indicate that a high rate of stimulated salivary flow was protective. But it could also be attributed to the observation in the bivariate analysis that the CVA subjects were taking a higher number of medications, some of them xerogenic, than were the non-CVA subjects, and these medications could reduce salivary flow ${ }^{24}$ (Table 1). The number of medications, or the number of xerogenic medications, was positively associated with a CVA in models that did not 
include the dependent-living status variable. These medication variables were most likely a function of the dependent-living status of the patient, and because they became nonsignificant in models containing living status, they were dropped from the final models shown in Tables 5 and 6.

The dental findings relative to the prevalence of dental caries and periodontal disease were not distinctly different between the subjects with and without a CVA (Table 3). The only difference noted in the bivariate analysis-a significantly higher proportion of teeth with attachment loss $>6 \mathrm{~mm}$ in the subjects with a CVA (Table 3)-was also observed in the logistic models (Tables 5 and 6). While it was significant, the OR was only 1.02 to 1.04 , indicating that it was at best making a minor contribution to the development of a CVA. This observation, however, supports the finding from a prospective study involving younger U.S. veterans, which showed that subjects with high levels of alveolar bone loss were 2.8 times more likely to develop a CVA than individuals with low levels of bone loss. ${ }^{9}$ It is also consistent with a case-control study involving insulindependent diabetics in which the cases at baseline had severe periodontitis, while the controls had a mild periodontal condition. ${ }^{25}$ Eight of 39 cases and 0 of 39 controls developed a stroke in the subsequent follow-up period, even though the level of diabetic control was comparable in the cases and controls. These data, especially the prospective studies, indicate a role for periodontal disease in the development of a CVA.

The most intriguing of the dental variables in the logistic regression models was that if the subjects had 15 to 28 teeth, they were 3.29 times more likely to have a CVA in the "all dentate" subject model (Table 5), and 3.79 times more likely to have a CVA in the "dentate dependent living" subjects model (Table 6). One could surmise that people of this age who have retained this many teeth, i.e., 22 teeth in the subjects without a CVA and 21.2 teeth in the subjects with a CVA, would have relatively better oral health than the subjects with only 1 to 14 teeth. This indeed had been found in a previous investigation in this group of subjects, where the logistic regression modeling procedure showed that having 15 to 28 teeth was a potential protective factor for coronary heart disease, primarily because of the better dental health of the subjects with 15 to 28 teeth compared to those with 1 to 14 teeth. ${ }^{26}$ Thus, it was unexpected to find that having 15 to 28 teeth was positively associated with a CVA. There was evidence that individuals with a CVA and 15 to 28 teeth had higher PIs, and were less likely to report brushing or flossing their teeth daily and not having their teeth cleaned on an annual basis, compared to those individuals without a CVA who also had 15 to 28 teeth (Table 7).

Among the oral hygiene parameters, "needing help in brushing one's teeth" and the reported annual visit to the dentist/hygienist for teeth cleaning reappeared as significant in the multivariate models (Tables 5 and 6). Because both of these variables were most important in the dependent-living subjects and involved others in the delivery of oral hygiene, the possibility exists that these variables represented a post-CVA condition. As noted previously, the need for help in brushing one's teeth could simply reflect the fact that many of the subjects with a CVA had reduced manual dexterity as a result of the CVA and required this extra care. However, this argument would not hold for the annual tooth cleaning, because those individuals who did receive an annual tooth cleaning, or extra care, were the ones who did not have a CVA.

The potential protective role of seeing the dentist at least once a year for teeth cleaning was elicited by the question: "How often do you have your teeth cleaned by a dentist or hygienist?" This question was intended to record a prior, if not lifetime, pattern of dental utilization. Thus, the finding that dependent dentate subjects who reported they did not have their teeth cleaned at least once a year were 4.76 times more likely to have had a CVA, suggests that a pattern of oral neglect might be associated with developing a CVA. If this is so, then intervention in the form of dental treatment or the promotion of dental health could have benefits in preventing or delaying the onset of a CVA, possibly by reducing the bacterial load on the teeth. 
All of the significant associations found in the reduced dentate model (Table 6) could lead to an increased accumulation of bacterial numbers on the tooth surfaces. A reduction in salivary flow could reduce the numbers of bacteria that are washed off the teeth by the saliva. Needing help in brushing implies that the level of oral hygiene practiced by the subject, even with help, could be deficient. The increased number of teeth and the increased percentage of teeth with attachment loss $>6 \mathrm{~mm}$ would increase the surface area upon which plaque could accumulate. This, coupled with the history of not having their teeth cleaned on a regular basis, suggests that a pattern of oral neglect, by promoting bacterial overgrowth on the dentogingival surfaces, could have predisposed a subject to CVA by mechanisms similar to those that have been proposed for the connection between dental disease and coronary heart disease ${ }^{9-15}$ and briefly described below.

Dentogingival surfaces in humans may be colonized by more than $10^{10}$ bacteria. ${ }^{14} \mathrm{~A}$ minuscule proportion of these bacteria gain access to the underlying tissues where they are quickly dispatched via the defensin system, ${ }^{27}$ an immune response, ${ }^{28}$ and if they are anaerobes, by the high tissue oxidationreduction potential and $\mathrm{pO}_{2}$ levels, ${ }^{14}$ all of which could result in a tissue-destroying inflammatory response. ${ }^{29}$ However, with poor oral hygiene, gingivitis, and gingival recession, the numbers of bacteria on the tooth surfaces could increase 2- to 10-fold. Individuals with a whole-mouth $\mathrm{PI}>1$ would have visible plaque accumulation around most of their teeth; and if there were more than 20 teeth per mouth, this could amount to more than $20 \mathrm{mg}$ of plaque wet weight, or $2 \times 10^{9}$ bacteria per dentition. (Visible plaque on a tooth weighs about $1 \mathrm{mg}$ and there are more than $10^{8}$ bacteria per mg of plaque.) If this plaque is associated with bleeding gingivitis, i.e., a PBS $>1$, then it is more likely that some of these bacteria, most likely Gram-negative, lipopolysaccharide (LPS)-containing anaerobes, ${ }^{30,31}$ would penetrate the gingival tissue and challenge the varied host defense mechanisms. Such chronic and persistent encounters with these LPS-containing invaders, while overwhelmingly successful on the part of the host relative to overt infections and septicemia, may appear in the systemic circulation as asymptomatic bacteremias, ${ }^{14,32,33}$ as an elevation of white blood cells (WBCs), ${ }^{34}$ as increase in serum cytokine levels, ${ }^{35}$ and/or as alterations in serum components of the clotting mechanisms. ${ }^{36}$

The incidence of bacteremia following something as routine as tooth brushing can be as high as $68 \%$ if there is underlying gingivitis. ${ }^{33}$ There is potential for a similar type of bacteremia to be present in our dependent-living subjects with plaque accumulations and gingivitis, and the extent of the bacterial challenge would increase with the number of teeth present. If these bacteremias occur frequently from the dentogingival surfaces in patients with poor oral hygiene and/or periodontal disease, then one would expect to see some blood-related changes in these individuals. In this regard, periodontal patients, relative to age- and gendermatched periodontally healthy controls, exhibited a significant increase in blood levels of fibrinogen and had significantly higher levels of WBCs, ${ }^{34}$ both of which have been described as independent risk factors for cardiovascular disease. ${ }^{36,37}$ This sequence of events could explain how poor oral hygiene habits and dental disease could place an individual at risk for serious cardiovascular consequences.

It thus becomes important to establish in prospective studies whether poor dental health or poor dental hygiene is a valid risk factor for a CVA, because dental health is a modifiable risk factor. Our results suggest that something as simple as annual teeth cleanings may be protective in an older, male population of U.S. veterans. The design of our cross-sectional study can only propose this possibility and provides no information as to whether these findings can be generalized to other populations.

\section{Acknowledgments}

This work was supported by USPHS research grant DE09412 from the National Institute of Dental Research and IP-AG- 
008808 from the National Institutes of Health. The assistance of George Taylor, Carol Gerlach, Kathy Curry, and Janice Stoll is acknowledged.

\section{REFERENCES}

1. Syrjanen J, Valtonen VV, Iivanainen M, Kaste M, Huttunen JK. Preceding infection as an important risk factor for ischemic brain infarction in young and middle-aged patients. $\mathrm{Br}$ Med $J$ 1988;296: 1156-1160.

2. Syrjanen J, Peltola J, Valtonen V, Iivanainen M, Kaste M, Huttunen JK. Dental infections in association with cerebral infarction in young and middleaged men. J Intern Med 1989;225:179-184.

3. Durack DT. Prevention of infective endocarditis. New Engl J Med 1995;332:38-44.

4. Lerner PI. Neurological complications in infective endocarditis. Med Clin North Am 1985;69:385-398.

5. Meurman JH, Rajasuo A, Murtomaa H, Savolainen S. Respiratory tract infections and concomitant pericoronitis of the wisdom teeth. $\mathrm{Br}$ Med $J$ 1995; 310:834-836.

6. Bartlett JG, Gorbach SL, Finegold SM. The bacteriology of aspiration pneumonia. Am J Med 1974; 56:202-207.

7. Bartlett JG. Anaerobic bacterial pneumonitis. Am Rev Resp Dis 1979;119:19-23.

8. Grau AJ, Buggle F, Ziegler C, et al. Association between acute cerebralvascular ischemia and chronic and recurrent infection. Stroke 1997;28:17141729.

9. Beck JD, Garcia RI, Heiss G, Vokonas PS, Offenbacher S. Periodontal disease and cardiovascular disease. J Periodontol 1996; 67:(suppl.):1123-1137.

10. Mattila KJ, Nieminen MS, Valtonen VV, et al. Association between dental health and acute myocardial infarction. Br Med $J$ 1989;298:779-781.

11. Mattila KJ, Valtonen VV, Nieminen M, Huttunen JK. Dental infection and the risk of new coronary events: Prospective study of patients with documented coronary artery disease. Clin Infect Dis 1995;20:588-592.

12. DeStefano F, Anda RF, Kahn HS, Williamson DF, Russell CM. Dental disease and risk of coronary heart disease and mortality. $\mathrm{Br}$ Med $J$ 1993;306: 688-691.

13. Syrjanen J. Vascular diseases and oral infections. $J$ Clin Periodontol 1990;17:497-500.

14. Loesche WJ. Periodontal disease as a risk factor for heart disease. Compendium Continuing Educ Dent 1995; 15:976-991.

15. Loesche WJ, Lopatin DE. Interactions between periodontal disease, medical diseases and immunity in the older individual. Periodontol 2000 1998;16:80105.
16. Loesche WJ, Abrams J, Terpenning MS, et al. Dental findings in geriatric populations with diverse medical backgrounds. Oral Surg Oral Med Oral Pathol 1995;80:43-54.

17. Hildebrandt GH, Loesche WJ, Lin C-F, Bretz WA. Comparison of the number and type of dental functional units in geriatric populations with diverse medical backgrounds. $J$ Prosthet Dent 1995;73: 253-261.

18. Marks RG, Magnusson I, Taylor M, Clouser B, Maruniak J, Clark WB. Evaluation of reliability and reproducibility of dental indices. $J$ Clin Periodontol 1993;20:54-58.

19. Loesche WJ. Clinical and microbiological aspects of chemotherapeutic agents used according to the specific plaque hypothesis. J Dent Res 1979:58: 2404-2412.

20. Loesche WJ, Schork A, Terpenning MS, Chen Y-M, Stoll J. Factors which influence the salivary levels of selected organisms in older individuals. $J$ Clin Microbiol 1995;33:2550-2557.

21. Shern RJ, Fox PC, Cain JL, Li S. A method for measuring the flow of saliva from the minor salivary glands. J Dent Res 1990;69:1146-1149.

22. Fox PC, Busch KA, Baum BJ. Subjective reports of xerostomia and objective measures of salivary gland performance. $J$ Am Dent Assoc 1987; 115:581-584.

23. Lamy PP. Drug prescribing for the elderly. Bull $N Y$ Acad Med 1981;57:718-730.

24. Gaziano JM, Buring JE, Breslow JL, et al. Moderate alcohol intake, increased levels of high-density lipoprotein and its subfractions, and decreased risk of myocardial infarction. New Engl J Med 1993;329: 1829-1834.

25. Thorstensson H, Kuylenstierna J, Hugoson A. Medical status and complications in relationship to periodontal disease experience in insulin-dependent diabetics. J Clin Periodontol 1996;23:194-202.

26. Loesche WJ, Schork MA, Terpenning MS, et al. The relationship between dental disease and coronary heart disease in elderly United States veterans. $J$ Am Dent Assoc 1998;129:301-311.

27. Martin E, Ganz T, Lehrer RI. Defensins and other endogenous peptide antibiotics of vertebrates. $J$ Leukoc Biol 1995;58:128-136.

28. Ebersole JL. Systemic humoral immune responses in periodontal disease. Crit Rev Oral Biol 1990;1: 283-331.

29. Page RC. The role of inflammatory mediators in the pathogenesis of periodontal disease. $J$ Periodont Res 1991;26:230-242.

30. Loesche WJ, Syed SA, Schmidt E, Morrison EC. Bacterial profiles of subgingival plaques in periodontitis. J Periodontol 1985;56:447-456.

31. Grossi SG, Genco RJ, Machtei EE, et al. Assessment of risk for periodontal disease. II. Risk indicators for alveolar bone loss. J Periodontol 1995;66: 23-29.

32. Hockett RN, Loesche WJ, Sodeman TM. Bacteremia in asymptomatic individuals. Arch Oral Biol 1977; 22:91-98

33. Silver JG, Martin AW, McBride BC. Experimental transient bacteraemias in human subjects with 
varying degrees of plaque accumulation and gingival inflammation. J Clin Periodontol 1977;4:92-99.

34. Kweider M, Lowe GDO, Murray GD, Kinane DF, McGowan DA. Dental disease, fibrinogen and white cell count; links with myocardial infarction? Scott Med $J$ 1993;38(3):73-74.

35. Offenbacher S, Katz VL, Fertik GS, et al. Periodontal infection as a possible risk factor for preterm low birth weight. J Periodontol 1996;67:(suppl.)11031113.

36. Lowe GDO, Kwider J, Murray GD, Kinane D, McGowan DA. Fibrinogen and dental disease-a coronary risk factor. In: Ernst E, Koenig W, Lowe GDO,
Meade TW, eds. Fibrinogen - A "New" Cardiovascular Risk Factor. Vienna: Blackwell-MZV; 1992: 201-204.

37. Gillum RF, Ingram DD, Makuc DM. White blood cell count, coronary heart disease and death: The NHANES I epidemiologic follow-up study. Am Heart $J$ $1993 ; 125: 855-863$.

Send reprint requests to: Dr. Walter Loesche, University of Michigan School of Dentistry, 1011 N. University, Ann Arbor, MI 48109-1078. Fax: 313/764-7406; email: WLoesche@umich.edu

Accepted for publication November 17, 1997. 